\title{
Alcoholic Beverage Consumption Behaviors Among Primary School Students
}

\author{
T Chotchai ${ }^{1, *}$
}

\author{
Sirindhorn College of Public Health Khon Kaen, 90/1 Anamai Road, Muang District, Khon Kaen Province, Thailand
}

\begin{abstract}
In 1997, WHO reported that $25 \%$ of pre-adolescents used to drink alcohol worldwide. The purpose of this cross-sectional research was to explore the alcoholic beverage consumption (ABC) behaviors among 380 primary school students in Khon Kaen Province, Thailand. Data were collected by questionnaires and analyzed by descriptive statistics. The results revealed that 68 students $(17.90 \%)$ used to drink and started drinking at 8 years old. For those who were in the alcohol consumption group, the average (SD) age onset of alcohol consumption was 10.78 (1.28); range 8-13 years. The most common reason for the first time of their ABC behaviors was curiosity in testing alcohol $(64.71 \%)$. Most of them shared the drink with friends $(75.00 \%)$. There were $60.29 \%$ and $48.52 \%$ of them that consumed alcohol after finishing their final examinations and birthday parties respectively. Most students can buy alcohol at the convenience stores $(66.17 \%)$. There were $69.11 \%$ who had alcohol consumption with their family members. Conclusion: Curiosity, peers, celebrating events and family members seemed to considerably influence on the students' ABC behaviors. Therefore, health-related agencies, schools and students' families may need to help together in solving this drawback behavior of young children.
\end{abstract}

Keywords : Alcoholic Beverage Consumption, Behaviors, Primary School Students

\section{INTRODUCTION}

The World Health Organization reported that preadolescents who have ever used alcohol was $25 \%$ worldwide. In low- and middle-income countries, the prevalence of alcohol use in $18 \%$ of boys and $14 \%$ of girls, aged between 13-15 years [1]. Worldwide, 5\% of all deaths of young people between the ages of 15 and 29 are attributable to alcohol use [2]. Alcohol use and drunkenness, along with other risk-taking behaviours, tend to emerge during the adolescent years. Indeed, alcohol is one of the most common psychoactive substances used by adolescents [3] [4]. Most young people begin using alcohol between the ages of 12 and 16, an age at which they gain increasing independence and spend more time outside the home unsupervised. Alcohol consumption in youth has several health effects. The US CDC (Centers for Disease Control and Prevention) reported at least 4,358 deaths in people age under 21 year [5] and alcohol-related emergency department visits are increasing at a greater rate than overall emergency department visits [6]. Thailand is a country in South-East Asia where alcohol use is a major cause of mortality and morbidity in youth. In 2007, almost 55\% of injured victims and $70 \%$ of arrested perpetrators in Thailand [7]. A Thai national survey of health risk behaviors demonstrated that approximately $40 \%$ of students had consumed alcohol in the last month during their lifetime [8].

\section{LITERATURE REVIEW}

As the previous all studies show that thirteen-to fifteenyear-olds are at high risk to begin drinking. A survey focusing on the alcohol-related problems experienced by
4,390 high school seniors and dropouts found that within the preceding year, approximately 80 percent reported either getting "drunk," binge drinking, or drinking and driving. More than half said that drinking had caused them to feel sick, miss school or work, get arrested, or have a car crash [9]. Some adolescents who drink later abuse alcohol and may develop alcoholism. Although these conditions are defined for adults in the DSM, research suggests that separate diagnostic criteria may be needed for youth [10].

\section{METHODOLOGY}

This study was a cross-sectional analytic study conducted at the primary schools in Khon Kaen province, Thailand. The study period was between March and April, 2018. The study population was primary school students who were willing to participate the study. Ethical permission for this study was obtained from the Ethics Committee of Sirindhorn College of Public Health Khon Kaen, Thailand (Ref. no 611016).

A stratified multi-stage random sampling was used to enroll primary schools for the study. The stratified method was based on the school size. Participants were systematic randomly selected by proportion to size of students in each school by using a student database. The required participants was calculated based on a previous study [11] which reported the prevalence of alcohol drinking in primary school students of $55.40 \%$. With a confidence of $95 \% \%$, power of $80 \%$, the required participants was 380 .

A formal letter to the school principal informed selected schools about the survey. The survey was scheduled a week later via phone call. Four school principals agreed to participate in the study. We collected data by using selfreported questionnaire. Participants were asked not to talk 
during the questionnaire completion. The survey took 4560 minutes.

The questionnaire was developed under the PRECEDE Framework, the Social Marketing Theory, the Triadic Influence Theory and the Theory of Planned Behavioral. It comprised of four parts; part A: demographic data (14 questions), part B: health related behaviors (37 questions), part C: ABC knowledge (10 questions), and part D: ABC behaviors and perceptions (55 questions). Part $\mathrm{C}$ responses were three-point scale (true, false, not sure). The knowledge score calculated from correct answer with the maximum of 10. Part D questions responses were Likert scale; five levels as characters "strongly disagree," "disagree," "somewhat disagree," "agree," and "strongly agree" scored as 1-5 point, respectively. The scores were reversed for negative questions; therefore, positive attitudes and appropriate perceptions yielded higher scores. The total scores were categorized as poor, sufficient, and good levels.

The dependent variable of this study was alcohol drinking defined by self-reported question. Those who reported as never drink alcohol defined as non-drinker, while those who ever drunk alcohol in any amount were in drinker group. Data analysis were made using Stata software version 12 (StataCorp, College Station, TX, USA). Participants were divided into two groups; drinkers and non-drinkers. Factors of both groups were compared by descriptive statistics.

\section{RESULTS \& ANALYSIS}

The average (SD) age of all students was 10.50 years (0.55). Male sex accounted for 33.16\%. Of those, 68 students $(17.90 \%)$ used to drink alcohol. The earliest age of starting drinking alcohol of students was 8 years. For those who were in the alcohol consumption group (68 students), the average (SD) age onset of alcohol consumption was 10.78 (1.28) years; range 8-13 years. The most common reason for first time of their alcohol consumption was for their curiosity in testing alcohol (44 students; 64.71\%). Types of beverages consumed of the students were wine cooler $(82.35 \%)$ and beer $(55.88 \%)$. Most of them shared the drink with friends (51 students; $75.00 \%)$. There were 41 students $(60.29 \%)$ and 33 students $(48.52 \%)$ consumed alcohol after finishing their final examinations and at their birthday parties respectively. Most students can buy their alcohol drinks at the convenience stores (45 students; $66.17 \%$ ). The average (SD) of the students' expenses on their alcoholic beverages per time was 84.29 (18.52); range 20-125 Baht. The location of drinking event was their own houses (41 students; 60.29\%). There were 47 students $(69.11 \%)$ who had alcohol consumption with their family members. The average (SD) numbers of family members who consumed alcohol was $2.12(0.58)$.
Table 1. Personal Characters of Surveyed Respondents Catagorized by Driking Behaviors.

\begin{tabular}{|c|c|c|}
\hline Variables & $\begin{array}{c}\text { Drinkers } \\
(\mathrm{n}=68)\end{array}$ & $\begin{array}{c}\text { Non- } \\
\text { drinkers } \\
(\mathrm{n}=312)\end{array}$ \\
\hline Male sex, \% & 61.39 & 26.24 \\
\hline Age, years (SD) & $\begin{array}{c}10.78 \\
(1.28)\end{array}$ & $\begin{array}{c}11.55 \\
(0.62)\end{array}$ \\
\hline Healthy, \% & 73.42 & 86.14 \\
\hline Living together with family, \% & 53.16 & 44.55 \\
\hline GPA in the last semester (SD) & $2.93(0.32)$ & $3.18(0.45)$ \\
\hline $\begin{array}{c}\text { Money received per day, baht } \\
\text { (SD) }\end{array}$ & $\begin{array}{c}48.16 \\
(20.77)\end{array}$ & $\begin{array}{c}49.65 \\
(21.05)\end{array}$ \\
\hline First birth order, \% & 21.52 & 14.85 \\
\hline $\begin{array}{c}\text { Number of people in the family } \\
\text { (SD) }\end{array}$ & 4.22 & $4.14(0.96)$ \\
\hline Living place: dormitory, \% & 27.85 & 14.85 \\
\hline $\begin{array}{c}\text { Parents' occupation: agriculture, } \\
\%\end{array}$ & 71.52 & 58.91 \\
\hline $\begin{array}{c}\text { Parents' marital status: } \\
\text { divorced/widowed, \% }\end{array}$ & 57.59 & 70.79 \\
\hline $\begin{array}{c}\text { Family incomes: <20,000 baht } \\
\text { per month, \% }\end{array}$ & 13.92 & 16.83 \\
\hline Having the plan of life, \% & 64.56 & 97.52 \\
\hline \multicolumn{2}{|c|}{} \\
\hline
\end{tabular}

Table 2. Alcoholic Beverage Consumption (ABC) Characteristics Among The 68 Respondents Who

\begin{tabular}{|c|c|}
\hline ABC behaviors & $\mathrm{n}(\%)$ \\
\hline \multicolumn{2}{|l|}{$\begin{array}{l}\text { Having } \mathrm{ABC} \text { behaviors in the past } 12 \\
\text { months }\end{array}$} \\
\hline Rarely & $63(92.65)$ \\
\hline 1-2 times per month & $5(7.35)$ \\
\hline 1-2 times per week & 0 \\
\hline Every day & 0 \\
\hline \multicolumn{2}{|l|}{ Age when started drinking (years) } \\
\hline$\leq 9$ & $2(2.94)$ \\
\hline 10 & $24(35.29)$ \\
\hline 11 & $32(47.06)$ \\
\hline 12 & $6(8.82)$ \\
\hline 13 & $4(5.88)$ \\
\hline \multicolumn{2}{|l|}{ The reason for the first drink } \\
\hline Experimentation & $44(64.71)$ \\
\hline Invited by friends & $15(22.06)$ \\
\hline Persuaded by family & $14(20.59)$ \\
\hline Advertising & $11(16.18)$ \\
\hline Challenged or peer pressure & $18(26.47)$ \\
\hline \multicolumn{2}{|l|}{ Type of beverages consumed } \\
\hline Wine & $56(82.35)$ \\
\hline Beer & $38(55.88)$ \\
\hline Local beverage & $19(27.94)$ \\
\hline Rice whiskey and four & $12(17.65)$ \\
\hline Liquor/Herbal liquor & $6(8.82)$ \\
\hline \multicolumn{2}{|l|}{ Shared a drink with someone } \\
\hline Alone & $39(57.35)$ \\
\hline Friends & $51(75.00)$ \\
\hline Family's members & $4(5.88)$ \\
\hline The occasion of each drink & \\
\hline Finished final examination & $41(60.29)$ \\
\hline
\end{tabular}




\begin{tabular}{|c|c|}
\hline Birthday party & $33(48.53)$ \\
\hline Party with friends & $28(41.18)$ \\
\hline Annual festival & $16(23.53)$ \\
\hline Alcohol obtained by & \\
\hline Yourself & $53(77.94)$ \\
\hline Family & $13(19.12)$ \\
\hline Source of beverages & $45(66.17)$ \\
\hline Convenience store & $32(47.06)$ \\
\hline Village groceries & $25(36.76)$ \\
\hline Retail shops in the village & $6(8.82)$ \\
\hline Groceries near their village & $4(5.88)$ \\
\hline Retail shops near their village & $12(17.65)$ \\
\hline $\begin{array}{c}\text { Expenses on alcohol beverages per } \\
\text { shopping trip (Baht) } \\
\leq 50\end{array}$ & $56(82.35)$ \\
\hline 50 & $41(60.29)$ \\
\hline Location of drinking event & $19(27.97)$ \\
\hline Own house & $8(11.76)$ \\
\hline Dormitory & $47(69.11)$ \\
\hline Restaurant/Store & $34(72.34)$ \\
\hline $\begin{array}{c}\text { Drinkers in the family } \\
\text { Yes; specify }\end{array}$ & $6(12.77)$ \\
\hline Father & $19(40.43)$ \\
\hline Mother & $2.12(0.58)$ \\
\hline Others & $65(95.59)$ \\
\hline Average (SD) numbers of drinkers in a \\
family & $3(4.41)$ \\
\hline Amount of each alcohol consumption & 0 \\
\hline Not more than 1 standard drink ${ }^{\mathrm{a}}$ & \\
\hline 2 standard drinks & \\
\hline More than 3 standard drinks & \\
\hline & \\
\hline
\end{tabular}

\section{CONCLUSION \& RECOMMENDATION}

Concurred with other studies, curiosity, peers, and family members seemed to considerably influence on the students' $\mathrm{ABC}$ behaviors [12]. In this study, alcoholic beverages seemed to be a social symbol of young people for celebration as seen in a study of Meier and colleagues [13]. Therefore, health-related agencies, schools and students' families may need to work collectively in solving such risk behaviors of young children [14] [15] [16].

Surprisingly, this study found that not only adolescent boys but also adolescents with the characteristic of having no future plans were more likely to have alcoholic drinks. This result might suggest health professionals, teachers and parents to concentrate on this young boys' health risk. As well as their well-being.

This study had both strengths and limitations. The study population was all early primary school students. So, results of this study may represent the early-adolescent age group. We also confirmed that the age onset of alcohol consumption was as early as 8 years. Further campaigns or intervention should be considered in students at early age of 9-10 years [11] [17] [18] [19]. The questionnaire in this study had a wide range of questions in regards of socioeconomic, knowledge, attitude, practice, perception, relationship, and behaviors. Even though the questionnaire had 116 questions, we did not study religion factor, school implementation/intervention on alcohol for students, and cultures. Finally, private schools which may have different student characteristics were not included in this study. Further research is needed to clear the hidden health risks of the very young aged adolescents. Curiously, according to law of Thailand, young people aged under 18 are not allowed to buy alcoholic drinks, but most of these young alcoholic drinkers in this study reported they obtained the alcoholic liquor by themselves. Such findings might suggest that there would be a middle people who could buy an alcoholic drink for these young people of there might be a shopkeeper illegally sell alcoholic drinks to young generation. Further research on the other influencing factors towards the drinking behavior of young adolescents is also needed.

\section{REFERENCES}

[1] WHO 2012 Global status report on alcohol 2012 [Internet] Geneva. Retrieved November 2014, fromwww.who.int/gho/publications/world_health_sta tistics/EN_WHS2012_Full.pdf

[2] WHO 2014Global status report on alcohol and health 2014 Attaining the nine global noncommunicable diseases targets; a shared responsibility [Internet] Geneva: Retrieved November 4, 2014, from

www.who.int/substance_abuse/publications/global_al cohol_report/ msb_gsr_2014_1.pdf?ua=

[3] Anderson P, Baumberg B 2006 Alcohol in Europe: a public health perspective. Brussels: European Commission: Retrieved December 10, 2015, from http://ec.europa.eu/health/Archive/ph_determinants/li fe_style/alcohol/documents/alcohol_europe_en.pdf

[4] Simons-Morton B G, et al 2009Gender specific trends in alcohol use: cross-cultural comparisons from 1998 to 2006 in 24 countries and regions Int J Public Health 54. $199-208$

[5] Hingson R W, et al 2015 Age of Drinking Onset and Injuries, Motor Vehicle Crashes, and Physical Fights After Drinking and When Not Drinking Alcoholism: Clinical \& Experimental Research 33 783-90

[6] Peter, M M, et al 2017 Alcohol-Related Visits to US Emergency Departments, 2001-2011 Alcohol and Alcohol, 52 119-25

[7] World Health Organization-Kobe Centre 2007 National report on violence and health Thailand WHO/WKC/Tech.Ser./05.4 Kobe, Japan: World Health Organization Centre for Health Development

[8] RuangkanchanasetrS, et al 2005 Youth risk behavior survey: Bangkok. Thailand Journal of Adolescent 36 227-35

[9] Ellickson, P L, et al 1996 Teenagers and alcohol misuse in the United States: By any definition, it's a big problem Addiction 91 1489-03

[10] Martin, C.S., et al 1996 Staging in the onset of DSMIV alcohol symptoms in adolescents: Survival/hazard analyses Journal of Studies on Alcohol 57 549-58 
[11] Samorabhumi C 2010Causal factors and prevention guideline of alcohol drinking behaviour among adolescent students in North-Eastern Thailand Journal of Education and Social Development 6 29-40

[12] Luecha, T, Peremans, L, Dilles, T, \& Van Rompaey, B 2019 The prevalence of alcohol consumption during early adolescence: a cross-sectional study in an eastern province, Thailand. International Journal of Adolescence and Youth 24 160-76

[13] Meier, B J, El-Gabri, D, Mvungi, M, Mmbaga, B T, Vissoci, J R N, \& Staton, C A 2019 Perceptions of alcohol use among injury patients and their family members in Tanzanian society Alcohol 2019 Jun 10 pii: S0741-8329(18)30083-1 doi:10.1016/j.alcohol.2019.06.001

[14] Aaron W, Ralph H 2014 The Burden of Alcohol Use Excessive Alcohol Consumption and Related Consequences Among College Students Alcohol Res 35 201-218

[15] Heidarali, A et al 2016 Factors Influencing School Health in Elementary Schools in Isfahan, Iran: A qualitative StudyInt J Community Based Nurse Midwifery 4 352-62

[16] Evaladekjael L et al, 2016 Students' drinking behaviour and perceptions towards introducing alcohol policies on university campus in Denmark: A focus group study Substance Abuse Treatment Prevention and Policy 11 11-7

[17] Hosiri T, Sittisun C, Limsricharoen K 2016Drinking Behavior and Its Prevalence in Grade 10th Students J Psychiatry Assoc Thailand61 3-14

[18] Center for Alcohol Studies Thailand 2016 Thailand Annual Report on Alcohol 2016 The National Statistical Office of Thailand

[19] Chaveepojnkamjorn W, Pichainarong N 2010 Factors associated with alcohol Consumption among male high school students in central Thailand Southeast Asian J Trop Med Public Health41 735-42 